\title{
Analytical Study of Storm Effect on Nighttime Enhancement at Low Latitude Station Jicamarca
}

\author{
Anita Agrawal ${ }^{1, ~ *, ~ K a l p a n a ~ M a s k i ~}{ }^{2}$, Surendra Kumar Vijay ${ }^{3}$, Satyadeo Mishra ${ }^{4}$ \\ ${ }^{1}$ Space Science Lab, Barkatullah University, Bhopal, India \\ ${ }^{2}$ Department of Education in Science \& Mathematics, Regional Institute of Education, NCERT, Bhopal, India \\ ${ }^{3}$ Department of Physics, Institute of Excellence in Higher Education, Bhopal, India \\ ${ }^{4}$ Department of Physics, Veer Sawarkar Government College, Obedullhaganj, Raisen, India
}

\author{
Email address: \\ anitagrwl3@gmail.com (A. Agrawal) \\ ${ }^{*}$ Corresponding author
}

\section{To cite this article:}

Anita Agrawal, Kalpana Maski, Surendra Kumar Vijay, Satyadeo Mishra. Analytical Study of Storm Effect on Nighttime Enhancement at Low Latitude Station Jicamarca. American Journal of Mechanics and Applications. Vol. 7, No. 2, 2019, pp. 15-20.

doi: 10.11648/j.ajma.20190702.11

Received: May 19, 2019; Accepted: June 20, 2019; Published: July 4, 2019

\begin{abstract}
This paper presents study of storm effect on nighttime enhancement at low latitude station Jicamarca. Jicamarca is an ionospheric station along the anomaly trough in the American sector. For this purpose hourly values of the critical frequency (foF2) parameter are taken at low latitude station Jicamarca $\left(12^{\circ} \mathrm{S}, 76.9^{\circ} \mathrm{W}\right.$; dip $\left.0.28^{\circ}\right)$. In the study, 39 severe storms were selected during the period2002 to 2014 based on the Dst index. With Dst $\leq-100 \mathrm{nT}$ is considered to be as severe storm. We have analyzed all the characteristics of nighttime enhancement at Jicamarca such as yearly mean amplitude, time of peak and duration of enhancement. To determine the seasonal effects, we grouped all data into three seasons' winter, summer and equinox using the four months of data for each season equinox (March, April, September and October), winter (January, February, November and December) and summer (May, June, July and August). It has been found in the study that the nighttime enhancement of foF 2 is affected by stormsat Jicamarca. It can be observed from the analysis of seasonal variation of mean amplitude during major storm and disturbed nights that mean amplitude of nighttime foF2 is higher in equinox and lowest in summer. Maximum peaks are observed during 22: 00 LT during both major storms and disturbed days. The outcome presented in the study provide comprehensive image of the effect of storm on nighttime enhancement.
\end{abstract}

Keywords: Nighttime Enhancement, $D_{\text {st }}$ Index, Severe Storm, Critical Frequency, Low Latitude

\section{Introduction}

Ionospheric storms are large-scale disturbances of the ionospheric structure and make it, dynamics erupted by a Coronal Mass Ejection from the sun. The strong enhancements of the solar wind energy generate large perturbations in the high-latitude ionosphere and thermosphere so; there are larger variability of the plasma density, which commonly propagate towards lower latitudes [1-2]. The ionospheric density or electron content is found to be either enhanced (positive storm) or depleted (negative storm) [3-6] depending on the local time of the storm commencement, season, latitude, and longitude of observation [7]. The scientific community shows wide interest in study of geomagnetic storms due its impact over space weather. At the time of a geomagnetic storm, the solar wind energy deposited into the magnetospheric polar cap region will eventually be dissipated into the ionosphere and thermosphere. To reduce effect on communication of ionosphere storm, a lower frequency should use as possible. The total duration of the magnetic storm is divided into four phases.

First phase begins when solar wind plasma arrives at the boundary of the magnetosphere with speed greater than stable solar wind is the sudden storm commencement (SSC), this cause of a sudden increase in horizontal component of the Earth's magnetic field.

Second phase is the initial phase through which the disturbance in H-component of the Earth's magnetic field does not alter significantly.

During the third phase, the significance of the H- compo- 
nent of the Earth's magnetic field depresses due to the enhancement of westward ring current.

The Fourth phase is recovery phase during which the value of the H- component of the Earth's magnetic field slowly recovers to the normal pre storm level.

The space community has great interest to study of geomagnetic storms because such storms are threat for satellite damage, communication break down and navigation problem. We focused on the effect of magnetic storm on nighttime enhancement parameters. We examined all the nighttime enhancement parameters such as seasonal dependent of mean amplitude of foF2, occurrence of peak time and duration during major storm and disturbed night.

The possible processes which might contribute to the magnetic storm causing ionospheric variations are:

Electromagnetic drift processes: this processes associated with storm time electric field

In this process, the magnetospheric convective electric field couples into the polar region where it quickly penetrates into the low and equatorial latitudes within a few seconds [8]. The buildup of charges field-aligned currents at the solar terminator give rise to dusk to dawn electric field which tends to oppose the dawn to dusk field. The effect of these two opposing electric field at the equatorial region depends on the direction of the interplanetary magnetic field $\mathrm{Bz}$, with southward (northward) direction supporting the eastward (westward) penetration fields. During rapid southward reversing of the interplanetary magnetic field $\mathrm{Bz}$, the magnetospheric dawn to dusk electric field can penetrate to the low latitudes before the development of any opposing shielding field and is called the under shielding effect. The daytime equatorial electrojet is enhanced by the under shielded eastward field during southward IMF Bz turning and the counter electrojet is caused by the over shielding westward field during northward IMF turning [9]. The equatorial and lowlatitude ionospheric response during the main phase of the storm in the first few hours is modulated by these convection electric fields.

Enhanced thermospheric circulation processes generated by auroral zone heating during magnetic storms and the resulting increased loss rate.

In enhanced thermospheric circulation processes, the storm time particle precipitation in the auroral region produce a series of energy transfer events through disturbed winds and tides, which propagate both toward the pole and the equator from the source region [10]. These thermospheric disturbances generate acoustic gravity waves which are visible as travelling atmospheric disturbances and travelling ionospheric disturbances. Generated travelling ionospheric disturbances in conjugate hemisphere auroral zones during geomagnetic storms, due to auroral zone heating can produce significant disturbances in the equatorial region ([11-12]). So there are disturbed winds, and disturbed thermospheric circulation are occurred and the equator ward rushes carry neutral molecular-rich airstream from the polar to the low and middle region and produce a negative effect due to enhanced recombination([4]; [10]). Due to lower ion drag during the local nighttime, the wind and TIDs are more effective in the night sectors. The thermospheric effects last longer into the recovery and post storm period because of the huge inertia of the winds [13].

Compression processes of plasma sphere by enhanced solar wind and changes in atmospheric composition due to enhanced thermospheric circulation.

The disturbed winds due to co rotation create an eastward current in the dayside middle latitudes, which in turn causes an accumulation of charges at the solar terminator due to conductivity difference in the dayside and the night side. These charges build up a westward electric field in the dayside and an eastward field electric field in the night side of low- and middle-latitude regions. Such effect is called ionospheric disturbance dynamo [13], in contrast to the quiet time dynamo action which produces eastward and westward electric field in the dayside and night side, respectively. The disturbance dynamo electric fields are produced late in the storm period, approximated 6 to 9 hours after storm commencement and mostly during the storm recovery phase when the geomagnetic activity is low ([13-14]). Therefore, the low- and middle-latitude ionospheric response to a geomagnetic storm can be the result of the combined effect of all three mechanisms which operate concurrently for a major part of the storm. The effect of geomagnetic storm that occurred on 15 may 2005 on GPS-TEC from Indian region and is observed that geomagnetic storms are serious threat to satellite based navigation system [15]. The VTEC response of the geomagnetic storm during solar minimum on 15 May 2005 shows that TIDs were responsible for the wave like nature in VTEC [16]. Wave like perturbation are excited by joule heating [17].

\section{Data and Method}

To study of storm effect on nighttime enhancement we have used foF 2 (Critical frequency) parameter. Critical frequency is the best parameter to study of storms effect over extended regions of the globe. For this purpose hourly values of the critical frequency (foF2) parameter were taken over Jicamarca $\left(12^{\circ} \mathrm{S}, 76.9^{\circ} \mathrm{W}\right.$; dip $\left.0.28^{\circ}\right)$. Jicamarca is an ionospheric station along the anomaly trough in the American sector. Hourly values of the critical frequency (foF2) parameter were collected from the site NGDC Space Physics Interactive data Resource (SPIDR) website (http://spidr.ngdc.noaa.gov) during period 2002 to2014. We have selected 39 severe storms during period 2002 to2014 based on the Dst index. With Dst $\leq-100 \mathrm{nT}$ is considered as severe storm. To determine the seasonal effects, we grouped all data into three seasons' winter, summer and equinox using the four months of data for each season. Data are arranged, winter (November, December, January and February), summer (May, June, July and August) and equinoctial (March, April, September and October). Disturbed nights are taken from World Data centre Kyoto, Japan. Storms are collected from World Data centre Kyoto, Japan. Five disturb nights were taken from each month of each year. We have analyzed 
all the characteristics of nighttime enhancement such as yearly mean amplitude, time of occurrence peak and duration of enhancement.

To determinate the nighttime enhancement, the similar criterion is applied as that adopted by Unnikrishan et al.[18]. Accordingly, a night-time foF2 enhancement was defined as the excess content foF 2 which remained after the exponentially decaying background of the diurnal content was subtracted from the total content. The exponentially decaying background part of foF 2 was found by drawing a foF2 graph for each night as shown in figure 1 and figure 2 where the dashed curves represent the background part of foF2. The maximum difference between the enhanced foF 2 and the background content gave the excess content, is known as amplitude. For the present study, only those enhancements which had amplitudes greater than $20 \%$ of the background content were considered. However, in the case of enhancements having multiple peaks, only the prominent peak was considered for the statistical study.

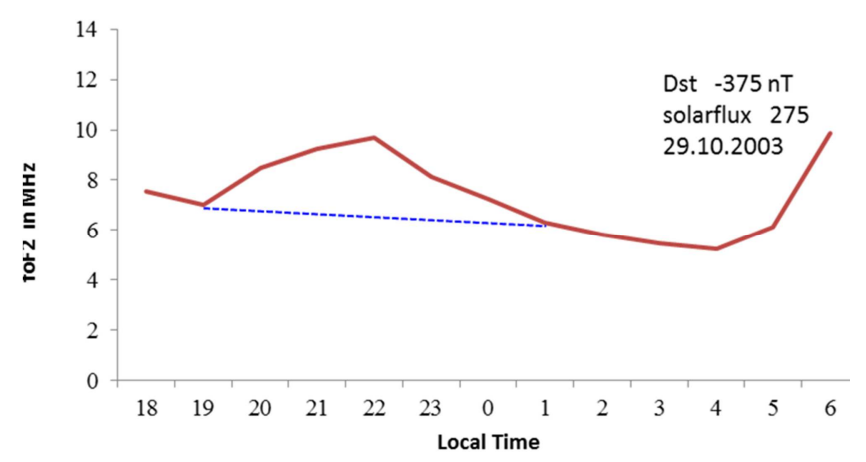

Figure 1. Example of nighttime enhancement during major storm.

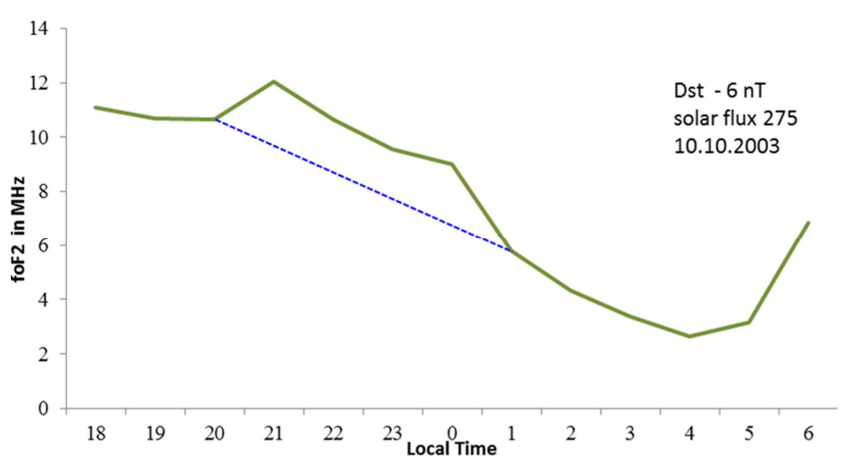

Figure 2. Example of nighttime enhancement during weak storm.

Table 1. List of occurrence of severe storms.

\begin{tabular}{lll}
\hline YEAR & MONTH (SSC) & Dst \\
& 17 April & -127 \\
& 19 April & -141 \\
2002 & 01 August & -101 \\
& 19 August & -102 \\
& 07 September & -155 \\
& 03 October & -140 \\
& 21 November & -101 \\
& 28 May & -129 \\
2003 & 16 June & -132 \\
& 11 July & -105 \\
& 17 August & -106 \\
\hline
\end{tabular}

\begin{tabular}{lll}
\hline YEAR & MONTH (SSC) & Dst \\
& 07 January & -149 \\
& 11 February & -109 \\
2004 & 03 April & -112 \\
& 22 July & -101 \\
& 24 July & -197 \\
& 30 August & -126 \\
& 07 November & -373 \\
& 17 January & -121 \\
& 07 May & -127 \\
2005 & 15 May & -263 \\
& 20 May & -103 \\
& 12 June & -138 \\
& 14 August & -106 \\
2006 & 31 August & -216 \\
2009 & 31 August & -131 \\
& 11 September & -147 \\
& 14 April & -111 \\
2012 & 14 December & -126 \\
& 14 January & -130 \\
& 09 March & -131 \\
& 23 April & -108 \\
2013 & 15 July & -127 \\
\hline \multirow{3}{*}{2014} & 01 October & -119 \\
\hline & 08 October & -105 \\
& 13 November & -108 \\
& 17 March & -132 \\
& 01 June & -119 \\
& 27 February & -102 \\
\hline
\end{tabular}

\section{Results}

\subsection{Yearly Mean Amplitude Variation During Major Storms and Disturbed Nights}

Figure 3 shows the yearly variation in nighttime foF 2 for major storms and disturbed nights during a solar cycle from 2002 2014. Dst $\leq-100 \mathrm{nT}$ is considered as major storm, due to lack of availability of data 39 storms are taken for study. Five disturb nights are used from each month of each year. From the figure it is seen that the value of mean amplitude is higher during 2013 in both major storms days and disturbed nights.

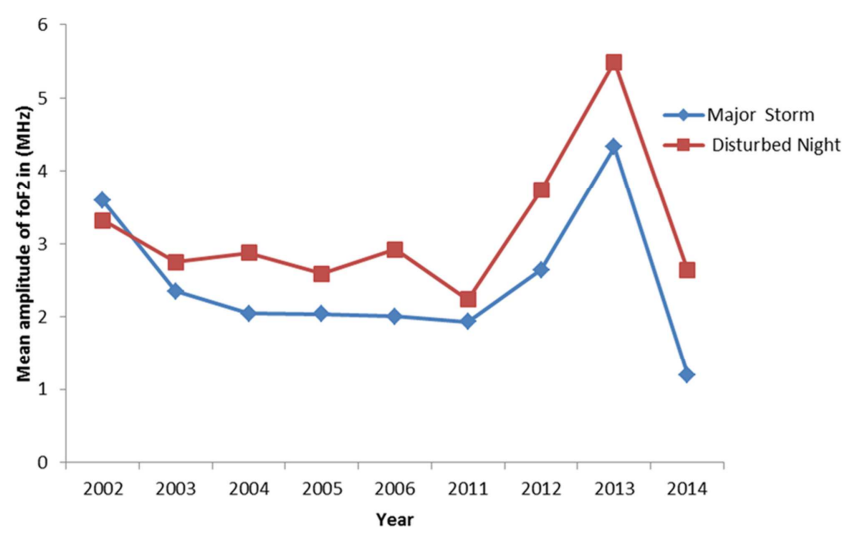

Figure 3. Yearly mean amplitude variation during major storms and disturbed nights.

\subsection{Seasonal Variation of Mean Amplitude During Major Storms and Disturbed Night}

Figure 4 represents the seasonal variation of mean ampli- 
tude during major storms and disturbed nights. It is found that mean amplitude is seasonal dependent. The value of mean amplitude is much greater in equinox than winter and summer during major storms and disturbed nights. In summer the value of mean amplitude is lower than the other two seasons during major storms period.

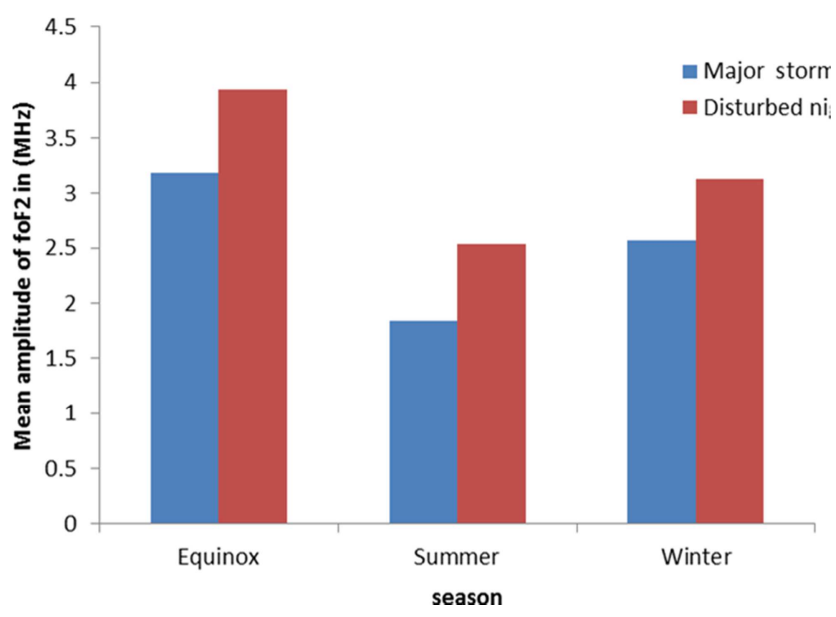

Figure 4. Seasonal variation of mean amplitude during major storms and disturbed nights.

\subsection{Time of Peak of Nighttime Enhancement in foF2 Dur- ing Major Storms and Disturbed Nights}

Figure 5 represents the time of peak of nighttime enhancement in foF2 during major storms and disturbed nights. It is seen from figure that maximum percentage of occurrence of enhancement peaks in foF2 occurred around 22:00 LT during major storms and disturbed nights. There is no enhancement is observed at 18:00-19:00 LT during major storm period, but at 19:00 LT 1\% peak value occurred. At post time hour 3:00LT occurrence is $11 \%$.

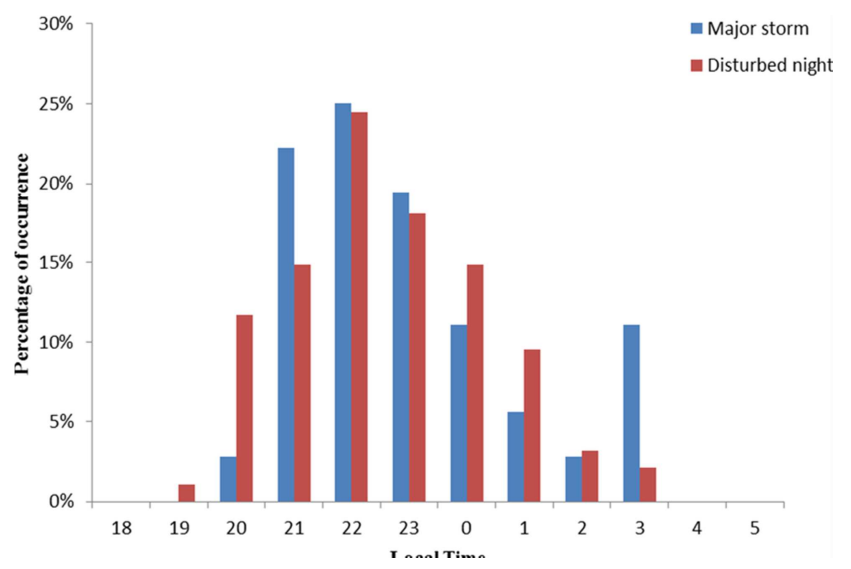

Figure 5. Timepeak of nighttime enhancement in foF 2 during major storms and disturbed nights.

\subsection{Duration of Nighttime Enhancement in foF2 During Major Storms and Disturbed Nights}

Figure 6 represents the duration of nighttime enhancement in foF2 during major storms and disturbed nights. It is seen from figure that maximum percentage of occurrence of dura- tion of enhancement occurred around 5 hours during major storms and 7 to 9 hours during disturbed nights.

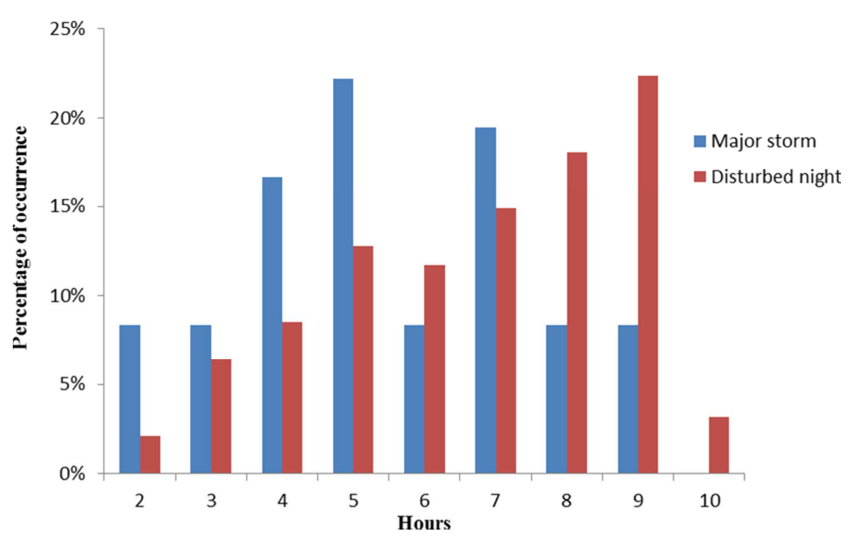

Figure 6. Duration of nighttime enhancement in foF2 during major storms and disturbed nights.

\section{Discussions}

Many possible explanations of this effect on the F-region of the ionosphere have been proposed. But none of these can claim to have explained all the storm phenomena with the proposed process. The value of mean amplitude is higher during 2013 in both major storms days and disturbed nights. 17 March 2013 a storm was observed. Dst value of this storm -132 nT, solar flux 122 unit, Kp about 6, sunspot number about $86, \mathrm{AE}$ is $2000 \mathrm{nT}$. This year is moderate solar activity period of $24^{\text {th }}$ solar cycle and sparked by coronal mass ejection. Strong PRE and associated intense scintillation may cause of this storm effect. Night time enhancement during 17 March 2013 has not discussed by previous workers.

We know that at low latitudes an ionospheric weather phenomenon is associated to variations in the $\mathrm{E} \times \mathrm{B}$ plasma drift. During day hours, ionization moves upward near the dip equator and in concert with the parallel motion down the field lines create the equatorial ionization anomaly. At the nighttime the low latitude ionosphere often exhibits plasma instabilities and bubbles that mostly vary in occurrence and strength from one night to the next. It is believed that the ionospheric weather at low, mid, and high-latitudes is caused by variations in the external forces that originate from the thermosphere, the magnetosphere, and the lower atmosphere [19]. Ionospheric weather and its related structures, gradients and variability have large influences on a variety of scientific systems and can strongly affect space weather system navigation, communication, and radar operations. If westward electric field take place it contributes to the positive ionosphere storms [20]. Mechanical effect of the winds that reduces the downward plasma along geomagnetic field lines and causes plasma convergence around the equator is major mechanism of the positive ionosperic storm. The downward effect of the wind is also caused of the positive ionosperic storm. The upwelling effect of the wind is cause of the severe negative ionosperic storm at high latitude, causes the positive storm at equatorial. Asymmetrical natural winds can make the positive storms asymmetrical with respect to the 
equator. A statically study on specification of equatorial scintillation index at the time of main phase of magnetic storm tells that if storm take place post midnight then scintillations are observed during main and recovery phase. If storm take place during daytime no scintillation is found during the night of the recovery phase [21]. When the storm occurs after sunset and before midnight, the F- layer is disturbed and scintillations are observed during undisturbed night. Due to day night, conductivity gradient eastward prompt penetration electric field becomes enhanced near the sunset. This enhanced eastward electric field forms plasma bubbles and irregularities of electron density, which causes scintillation of satellite signal. The combined effect of gravity and eastward electric fields, excite plasma instability in the nighttime $\mathrm{F}$ region equatorial ionosphere due to vertical upward density gradient. Roshani et al. [22] have examined the effect of solar and geomagnetic on critical frequency of the F2 layer. They have used ionospheric data at Low, mid and high latitude station. The value of foF 2 increased from their normal value at all the three latitudes, since storms take place around the same time. A very interesting feature that can be seen in the figures is that the increase of foF 2 at Low latitude is much more intense as compare to high and mid latitude. They have found that the effect of solar and geomagnetic storm disturbances is maximum at the low latitude and minimum at the high latitude at the time of geomagnetic storm. Although low latitude ionospheric weather phenomenon is related to variations in the $\mathrm{E} \times \mathrm{B}$ plasma drift, which is prominent during the daytime. The ionization lifts upward near the dip equator and in concert with the parallel motion down the field lines creates the equatorial ionization anomaly. The largest density values occur in the ionization anomaly peaks with day to day variations [23]. The largest variability found at high latitudes where convection electric fields originating from the magnetosphere and particle precipitation can dramatically change the plasma distribution. Vertical radio sounding techniques (ionosondes) have provided us with much more of the information about the ionized upper atmospheric layers. Unnikrishan et al. [18] observed that mean amplitude is seasonal dependent this match with our result, seasonal variation of mean amplitude during major storm and disturbed nights. The main seasonal changes associated with thermosphere or ionosphere storm [8].

\section{Conclusions}

The outcome presented in this study provide comprehensive image of the effect of storm on nighttime enhancement. Main characteristics of night-time enhancements during severe storms and disturbed nights are observed. The main results are converged as follows:

The night enhancement of foF2 at Jicamaraca is affected by storms.

The mean amplitude of foF2 is higher during disturbed nights than severe storm.

From yearly analysis it is observed that the mean amplitude of foF2 is highest in the year of 2013 and lowest in the year of 2004 during severe storm and disturbed nights.

It is seen from the analysis of seasonal variation of mean amplitude during major storm and disturbed nights that mean amplitude of nighttime foF2 is higher in equinox and lowest in summer.

Maximum peaks are observed during 22:00 LT during both major storms and disturbed days.

\section{Acknowledgements}

The author (Anita Agrawal) would like to thank Space Physics Interactive Data Resource (SPIDR) website (http://spidr.ngdc.noaa.gov) for providing data of ionospheric parameters foF2. From World Data centre Kyoto, Japan.

\section{References}

[1] Ho, C. M., Mannucci A. J., Lindqwister U. J., Pi X., Tsurutani B. T. (1996), Global ionosphere perturbations monitored by the worldwide GPS network. Geophysical Research Letters, v. 23, N 22, p. 3219-3222.

[2] Förster M., Jakowaski N. (1995), the nighttime winter anomaly (NWA) effect in the American sector as a consequence of inter hemispheric ionospheric coupling. PAGEOPH, Vol. 127, N2, 447-471.

[3] Prölss, G. W. (1987), Storm-induced changes in the thermospheric composition at middle latitudes, Planet. Space Science, $35,807-811$.

[4] Rishbeth, H. (1991), Ionospheric Science and Geomagnetism, Quarterly Journal of the Royal Astronomical Society, Vol. 32, NO. 4/DEC, P. 409.

[5] Fuller-Rowell et al., 1994; Fuller-Rowell, T. J., Codrescu, M. V., Moffett, R. J., Quegan, S., Rishbeth, H. (1994), Response of the thermosphere and ionosphere to geomagnetic storms, Journal of Geophysical Research, 101, 2343-2353.

[6] Field, P. R., H. Rishbeth, R. J. Moffett, D. W. Idenden, T. J. Fuller-Rowell, G. H. Miiward, and A. D. Aylward (1998), Modelling composition changes in F-layer storms, Journal of Atmospheric and Solar Terrestrial Physics, 60 (5), 523-543.

[7] Bitap Raj Kalita, Ruma jyoti Hazarika, Geetashree Kakoti1 P. K. Bhuyan1, D. Chakrabarty G. K. Seemala3 K. Wang S. Sharma, T. Yokoyama, P. Supnithi, T. Komolmis, C. Y. Yatini, M. Le Huy, and P. Roy (2016), Conjugate hemisphere ionospheric response to the St. Patrick's Day storms of 2013 and 2015 in the $100^{\circ}$ E longitude sector" J. Geophys. Res. Space Physics, 121.

[8] Kikuchi, T., H. Lühr, T. Kitamura, O. Saka, and K. Schlegel (1996), Direct penetration of the polar electric field to the equator during a DP 2 event as detected by the auroral and equatorial magnetometer chains and the EISCAT radar, J. Geophys. Res., 101, 17, 161-17, 173.

[9] Kikuchi, T., Y. Ebihara, K. K. Hashimoto, R. Kataoka, T. Hori, S. Watari, and N. Nishitani (2010), Penetration of the convection and over shielding electric fields to the equatorial ionosphere during a quasi periodic DP 2 geomagnetic fluctuation event, J. Geophys. Res., 115, A05209. 
[10] Fuller-Rowell, T. J., Codrescu, M. V., Moffett, R. J., Quegan, S., Rishbeth, H. (1996), Response of the thermosphere and ionosphere to geomagnetic storms, Journal of Geophysical Research, 101, 2343-2353.

[11] Hajkowicz, 1991) Hajkowicz, L. A., (1995), Ionospheric response to auroral substorms during sunspot maximum (198082), Annales Geophysicae, 13, 95.

[12] Fesen, C. G., G. Growley, and R. G. Roble (1989) Ionospheric effects at low latitude during the March 22, 1979, geomagnetic storm, Journal of Geophysical Research, 94 (A5), 54055417.

[13] Blanc, M., and A. Richmond (1980), the ionospheric disturbance dynamo, J. Geophys. Res., 85, 1669-1686.

[14] Scherliess, L., and B. G. Fejer (1997), Radar and satellite global equatorial $F$ region vertical drift model, J. Geophys. Res., 104, 6829-6842.

[15] Dashora, N., Sharma, S., Dabas, R. S., Alex, S., Pandey, R. (2009), Large enhancement in low latitude total electron content during $15^{\text {th }}$ May 2005 geomagnetic storm in Indian zone, Annales Geophysicae, 27, 1803-1820.

[16] Jain, S., and Vijay, S. K. (2000) Solar and magnetic activity control on nighttime enhancement in IEC at equatorial anomaly latitude, Indian Journal of Physics, Vol. 74 (B), 261265.

[17] Borries, C., Jakowski, N., and Wilken, V. (2009) Storm induced large scale TIDs observed in GPS derived TEC, Annales Geophysicae, 27, 1605-1612.
[18] Unnikrishanan, K., R. B. Nair, and C. Venugopal (2002) A comparative study of night-time enhancement of TEC at a low latitude station on storm and quiet nights including the local time, seasonal and solar activity dependence, Annales Geophysicae, 20, 1843-1850.

[19] R. W. Schunk, F. A. Nagy, (2000), Ionospheres. Cambridge University Press, Cambridge, UK.

[20] Balan N., Y. Otsuka, M. Nishioka, J. Y. Liu and G. J. Bailey (2013), Physical mechanism of the ionospheric storms at equatorial and higher latitudes during the recovery phase of geomagnetic storms. Journal of Geophysical Research, 118, $1-10$.

[21] Baiju Dayanadan and Brij Mohan Vyas (2013), Study of VHF Ionospheric Scintillation during Geomagnetic storm at Udaipur, International Journal of Astronomy, 2 (1), 1-10.

[22] Roshni Atulkar, Shivangi Bhardwaj, Prakash Khatarkar, Purushottam Bhawre, P. K. Purohit (2014), Geomagnetic disturbances and its impact on ionospheric critical frequency (foF2) at high, mid and low latitude region American Journal of Astronomy and Astrophysics; 2 (6): 61-65 Published online December 19, 2014, (http://www.sciencepublishinggroup.com/j/ajaa).

[23] Khatarkar P. Purohit P. K., Gwal. A. K., (2014), Study of ionospheric F2 layer characteristics at low, mid and high latitudes. International Journal of Science and Research (IJSR) vol. 3 Issue 9, ISSN 2319-7064. 